\title{
Impulse Response of Inflation to Economic Growth Dynamics: VAR Model Analysis
}

\author{
Doan Van DINH ${ }^{1}$
}

Received: June 15, 2020 Revised: July 05, 2020 Accepted: August 10, 2020

\begin{abstract}
The study investigates the impact of inflation rate on economic growth to find the best-fit model for economic growth in Vietnam. The study applied Vector Autoregressive (VAR), cointegration models, and unit root test for the time-series data from 1996 to 2018 to test the inflation impact on the economic growth in the short and long term. The study showed that the two variables are stationary at lag first difference I(1) with $1 \%, 5 \%$ and $10 \%$; trace test indicates two cointegrating equations at the 0.05 level, the INF does not granger cause GDP, the optimal lag I(1) and the variables are closely related as R2 is $72 \%$. It finds that the VAR model's results are the basis to perform economic growth; besides, the inflation rate is positively related to economic growth. The results support the monetary policy. This study identifies issues for Government to consider: have a comprehensive solution among macroeconomic policies, monetary policy, fiscal policy and other policies to control and maintain the inflation and stimulate growth; set a priority goal for sustainable economic growth; not pursue economic growth by maintaining the inflation rate in the long term, but take appropriate measures to stabilize the inflation at the best-fitted VAR forecast model.
\end{abstract}

Keywords: Macroeconomic Policies, Vector Autoregressive, Variance Decomposition, Monetary Policy

JEL Classification Code: O11, F43, C23, C2

\section{Introduction}

The research applied VAR model for the data on inflation index and economic growth annual. The data is collected in the period from 1996 to 2019 to test stationarity, cointegration and nuclear test Granger results, hereby assessing inflation impact on economic growth. The literature shows that the inflation is the allowable level that is suitable for good GDP growth, but if it passes over this level (below level or upper level), it will cause downward economic growth and start damaging the economy. Hence, the major literature focused on the analysis of the inflation impact on economic growth and found that the inflation and GDP growth were causalities one-way or two-way to set up a fit forecast model. Other authors studied China's relationship between economic

${ }^{1}$ First Author and Corresponding Author. Faculty of Finance and Banking, Industrial University of Ho Chi Minh City, Vietnam [Postal Address: 12 Nguyen Van Bao, Ward 4, Go Vap, Ho Chi Minh, 70000, Vietnam] Email: citydinhninh@yahoo.com; doanvandinh@iuh.edu.vn

(c) Copyright: The Author(s)

This is an Open Access article distributed under the terms of the Creative Commons Attribution Non-Commercial License (https://creativecommons.org/licenses/by-nc/4.0/) which permits unrestricted non-commercial use, distribution, and reproduction in any medium, provided the original work is properly cited. growth and inflation in recent years and used the method of systematic discrepancies between cross-sectional and time-series Engel curves to construct alternative estimates of Chinese growth and inflation. These results indicated that the real inflation was still high and consumption growth was overstated (Emi, Jón, \& Miao, 2016).

The author's contribution to the article explores the inflation rate impact on economic growth in Vietnam from 1996 to 2019. The author applies the VAR model to find the optimum inflation lag for the GDP growth of Vietnam, it is causality one-way or two-way and any more. It means that inflation needs to be maintained at a reasonable level to reach good economic growth. If inflation is higher than this level, the growth possibility goes down. Hence, the article applies the VAR model that has two variables that are the GDP as dependent variable, and inflation rate as the independent variable (Dinh, 2019c). To keep the GDP growth target, the Government forces the loosening or tightening of fiscal and monetary policies that increased or decreased inflation rate reasonably. Therefore, the empirical results on the inflation and economic growth showed that they had a close relationship and their relationship is negative and positive. Besides, they are causal relationship one-way. It means that the economic growth rate displays a causal relationship 
with the inflation rate, but the inflation rate doesn't display a causal relationship with the economic growth rate (Dinh, 2020b).

In this paper, the author applies a Vector Autoregressive (VAR) model to evaluate whether the inflation rate impacts on GDP, and how it does impact. The results of the paper demonstrate that the change in Vietnam's inflation rate impacts on the GDP and find the fittest forecast model of economic growth. Why is it the case? These contributions play an important role in planning, orienting or setting an appropriately-adjusted monetary policy to promote the economic growth. The government should not make mistake deciding on monetary policy to control the inflation and economic recession. The remainder of the paper is organized as follows: Section 2 reviews the literature; Section 3 explains the data and methodology of economics; Section 4 summarizes the results; Section 5 discusses the findings and the last section gives conclusions.

\section{Literature Review}

Some studies evaluated the relationship between the inflation rate and GDP growth of Pakistan by using the annual data of inflation and GDP growth and using the different techniques such as OLS, FMOLS, TAR and threshold model to estimate the real relationship between the concerned variables. These results indicated that the positive relationship between the inflation rate and economic growth rate of Pakistan was at the inflation threshold of 5.5\% to $9 \%$ and confirmed the nonlinear relationship between them (Gulnaz, Sidra, \& Atta, 2017). The high inflation was always correlated with increased price variability, which could lead to uncertainty about the future profitability of investment projects. Thus, the major purpose of this article was to reexamine the existence of relationship between the inflation and economic growth of Pakistan, and the method of Ordinary Least Squares (OLS) is used to analyze empirically the impact of inflation on GDP growth. The results showed that the prevailing inflation was harmful to the GDP growth after a certain threshold. However, the results were a negative inflation-growth relationship that was found to exist in the economy of Pakistan (Muhammad, Imran, \& Fatima, 2011).

There are theoretical and empirical studies on the impact of inflation on economic growth (Robert, 2013; Faraji \& Kenani, 2012; Kanchan \& Chandan, 2011; Fakhri, 2011; Thanabalasingam, 2013). Their results show that there was no consensus on the relationship between inflation and economic growth in both theoretical and empirical studies. These authors indicated that the results mostly depend on the assumptions adopted in the study. Accordingly, the theoretical literature indicated that the relationship between the inflation and economic growth could be positive, negative or neutral.
Moreover, the empirical results had two models: linear and nonlinear relationships (Al-Khulaifi, 2018; Mustafa, \& Sivarajasingham, 2019). Keynes's research indicated that, in the short term, there would be a trade-off between the inflation and growth, i.e., a high inflation rate made GDP growth and during this period, growth and inflation rate were positively correlated. However, in the long term, if the inflation rate increased continuously to promote GDP growth, the GDP would decrease (Mishkin, 2016).

Most of the previous studies also applied a simple regression model and a correlation coefficient to examine empirically the relationship between the inflation and economic growth, e.g., some authors found the inflation threshold in Bangladesh based on the Ordinary Least Squares method to forecast an inflation of $8 \%$ (Khairul \& Md. Sazib, 2017). Another study also determined the relationship between the GDP growth rate and inflation rate in Ghana and applied the methods of scatter plot, correlation analysis and simple linear regression estimated by OLS, and the result showed that there was a strong negative linear relationship between GDP growth rate and inflation rate in Ghana (Patrick, Prudence, \& Edmond, 2013; Nurlanova, Omarov, \& Satpayeva, 2020). The authors studied the relationship between the inflation and GDP growth after the trade and financial liberalization in Brazil and applied the estimate model for the case of Brazil (Carolina, 2015). The main objective of was to investigate the relationship between the inflation and economic growth in Bangladesh and applied unit root or stationary and Dickey-Fuller Test to have results and these results indicated that Bangladesh had a statistically significant long-run positive relationship between the inflation rate and economic growth (Shapan, 2016). The literature showed that each research paper applied OLS model and some other models to estimate and forecast the results in each context of inflation, specific GDP growth of the country. Therefore, this article also applies the OLS model and some other tests to estimate and forecast the inflation rate and GDP growth rate of Vietnam.

Moreover, most of the literature limits analysis data within the scope of a country. Thus, the author focuses on the impact analysis of both the inflation rate and GDP to consider whether the inflation rate impacts on GDP growth and what is the adequate inflation level to grow the economy best. To solve these issues, the author applies the VAR model for Vietnam's data of the GDP growth and inflation rate to analyse their impact (Dinh, 2018).

It is known that VAR model is the most common estimation method for economic growth forecast models. Regression analysis is like other deductive methods. The objective of the paper is to collect a random sample from the GDP growth and inflation rate and use it to estimate their characteristic (Dinh, 2020a). 


\section{Research Methodology}

As it is known, modern econometric models are used to demonstrate the impact, as well as the effects of inflation and economic growth in the Vietnamese economy. Therefore, the Vector Autoregression (VAR) model was selected in this study for the following reasons: firstly, the variables in the model are in the form of time series and autocorrelated variables, the VAR model is suitable for handling such time series and autocorrelation problems. Secondly, the VAR model considers the dynamic and causal relationships among economic variables, which is an advantage that classical regression models cannot do, so VAR is appropriate in policy analysis as well as macroeconomic planning. Finally, the VAR model is also used by many leading scholars to study inflation and economic growth, so it is easier to continue using VAR in comparing research results (Kumar \& Paramanik, 2020).

Thus, the relationship between the inflation rate and GDP growth of Vietnam is considered whether they have positive or negative and linear or nonlinear relationship and find the inflation impact on economic growth. So, the author uses the following econometrics model for analysis. To determine cointegration model, it is tested by first unit root to determine if it is lag and trend. Hence, the model is tested by unit root as follows:

Unit root test is a commonly-used tool to test whether a time series is stationary. Dickey and Fuller (1981) introduced Dickey and Fuller (DF) tests and extended Dickey and Fuller (ADF) tests. This study applies the ADF test to perform unit root test (Dinh, 2019a). Specifically, according to Dickey and Fuller (1981) the ADF extended unit test model has the form:

Hereby, Vietnam gross domestic product growth (GDP) variable is called the dependent variable and Vietnam inflation rate (INF) variable is called the independent variable, so it is written as follows:

$$
\begin{gathered}
\Delta_{G D P_{t}}=\alpha_{0}+\beta G D P_{1-1}+\sum_{j=1}^{n} \gamma_{j} \Delta_{G D P_{t-i}+\varepsilon_{t}} \\
\text { And } \Delta_{G D P_{t}}=\alpha_{0}+\delta_{t}+\beta G D P_{1-1}+\sum_{j=1}^{n} \gamma_{j} \Delta_{G D P_{t-i}+\varepsilon_{t}}
\end{gathered}
$$

In which:

$$
\Delta_{G D P_{t}}=G D P_{t}-G D P_{t-1}
$$

$G D P_{t}$ : time-series data over time;

n: stationary time series;

$\varepsilon$ white noise

The model (2) is different from the model (1), where there is an additional trend variable in time $t$. The trend variable is a value from number 1 to number $n$. White noise is the term for random errors, the assumption that it has an average of zero, the variance is constant and non-correlation.
The results of the ADF test are often very sensitive to the choice of the length of the stationary n, so the Akaike's Information Criterion (AIC) Akaike (1973) is used to select the optimal $\mathrm{k}$ for the ADF model. Specifically, the value of $\mathrm{n}$ is chosen such that the minimum AIC.

Testing hypothesis:

$H_{0}: \beta=0\left(G D P_{t}\right.$ is the non-stationary data time-series)

$H_{1}: \beta<0\left(G D P_{t}\right.$ is the stationary data time-series).

To test the hypothesis $H_{0}$, the calculated value $(\mathrm{t})$ is compared with the critical value. If the calculated value (t) is greater than the critical value, the hypothesis $H_{0}$ is rejected, i.e. the data series is stationary and vice versa, the hypothesis $H_{0}$ is accepted, i.e. the data is non-stationary.

To analyse time series with ordinary least squares, it is the assumption that the variances and means of the series are constants that are independent of time (i.e. the processes are stationary). Non-stationary time series (or unit root variables) don't meet this assumption, so the results from any hypothesis test will be biased or misleading. These series have to be analyzed with different methods. One of these methods is called cointegration. The cointegration is where two I (1) time series $X_{t}$ and $Y_{t}$ can be described by the stationary process (Dinh, 2020b).

The equation OLS is written: $\varepsilon_{t}=G D P_{t}-\beta_{2} I N F_{\mathrm{t}}$ where $\beta_{2}$ is a stationary process. Let $G D P_{t}$ and $I N F_{t}$ be cointegrated if there exists a vector when $G D P_{t}$ and $I N F_{t}$ are in equilibrium. The reason for unit roots and cointegration tests is to avoid the spurious regression.

Tests for Cointegration: Tests for cointegration identify stable, long-run relationships between sets of variables. However, (Rao, 2007) notes that if the test fails to find such a relationship, it isn't proof that one doesn't exist, it only suggests that one may not exist. Three of the most popular tests are Engle-Granger, Phillips-Ouliaris and Johansen test. However, the Johansen test is applied because it is another improvement over the Engle-Granger test. It avoids the issue of choosing a dependent variable as well as issues created when errors are carried from one step to the next. As such, the test can detect multiple cointegrating vectors (Dinh, 2019a).

The VAR model describes the evolution of a set of $\mathrm{k}$ variables (called endogenous variables) over the same sample period $(\mathrm{t}=1, \ldots, \mathrm{T})$ as a linear function of only their past values. The variables are collected in a k-vector $((\mathrm{k} \times 1)$-matrix $) Y_{t}$, which has as the $\mathrm{i}$ th element, $Y_{i, t}$, the observation at time $\mathrm{t}$ of the $\mathrm{i}$ th variable. Assuming, if the $i^{\text {th }}$ variable is GDP, then $Y_{i, t}$ is the value of GDP at time $t$ The VAR model is considered as follows:

$$
G D P_{1 t}=\alpha_{0}+\sum_{j=1}^{n} \alpha_{i} G D P_{t-i}+\sum_{j=1}^{n} \beta_{j} I N F_{t-j}+U_{1 t}
$$


Table 1: Unit root at Lag Length: (0) and (1) of the GDP and INF variables

\begin{tabular}{|c|c|c|c|}
\hline \multicolumn{2}{|c|}{ Model: GDP of a unit root - Lag Length: 0 (Automatic - based on SIC, max lag =4) } & t-Statistic & Prob.* \\
\hline \multicolumn{2}{|c|}{ Augmented Dickey-Fuller test statistic } & -3.805090 & 0.0092 \\
\hline \multirow[t]{3}{*}{ Test critical values: } & $1 \%$ level & -3.769597 & \\
\hline & $5 \%$ level & -3.004861 & \\
\hline & $10 \%$ level & -2.642242 & \\
\hline \multicolumn{2}{|c|}{ Model - INF of a unit root - Lag Length: 0 (Automatic - based on SIC, max lag =4) } & t-Statistic & Prob.* \\
\hline \multicolumn{2}{|c|}{ Augmented Dickey-Fuller test statistic } & -2.958428 & 0.0548 \\
\hline \multirow[t]{3}{*}{ Test critical values: } & $1 \%$ level & -3.769597 & \\
\hline & $5 \%$ level & -3.004861 & \\
\hline & $10 \%$ level & -2.642242 & \\
\hline \multicolumn{2}{|c|}{ Model: $D(I N F)$ of a unit root, Lag Length: 1 (Automatic - based on SIC, max lag =4 } & t-Statistic & Prob.* \\
\hline \multicolumn{2}{|c|}{ Augmented Dickey-Fuller test statistic } & -5.821173 & 0.0001 \\
\hline \multirow[t]{3}{*}{ Test critical values: } & $1 \%$ level & -3.808546 & \\
\hline & $5 \%$ level & -3.020686 & \\
\hline & $10 \%$ level & -2.650413 & \\
\hline
\end{tabular}

*MacKinnon (1996) one-sided p-values.

$$
I N F_{2 t}=\beta_{0}+\sum_{j=1}^{n} \beta_{j} I N F_{t-j}+\sum_{j=1}^{n} \alpha_{i} G D P_{t-i}+U_{2 t}
$$

In which: $U_{1 t}$ and $U_{2 t}$ are white noise.

As mentioned above, the major objective of the paper is to analyse and evaluate the VAR model of the inflation rate and GDP growth rate as well as optimal lag, impulse response and the goodness-fit VAR model.

To consider the VAR Granger Causality from (3) and (4) equations, the hypotheses are as follows:

The hypothesis $H_{1}: \sum \alpha_{i}=0 ; \sum \beta_{i} \neq 0$; the economic growth rate causes the inflation rate (GDP $\rightarrow$ INF), one-way Granger.

The hypothesis $H_{2}: \sum \alpha_{i} \neq 0 ; \sum \beta_{j}=0$; the inflation rate causes the economic growth rate (INF $\rightarrow$ GDP), oneway Granger

The hypothesis $H_{3}: \sum \alpha_{i} \neq 0 ; \sum \beta_{j} \neq 0$; both the inflation and the economic growth rates cause interactions (INF $\leftrightarrow$ GDP), two-way Grange, where the arrow indicates causality.

The Granger causality test assumes that the relevant information to predict individual variables, that are the GDP and $\mathrm{INF}$, is only included in the time series data for these variables.

As VAR model was mentioned, each variable is linearly dependent on the lag values of this variable and the lag values of the other variables. General VAR model is written as follows:

$$
Y_{t}=A_{1} Y_{t-1}+A_{2} Y_{t-2}+\ldots .+A_{n} Y_{t-n}+s_{t}+U_{t}
$$

In which: $Y_{t}=\left[\begin{array}{c}Y_{1 t} \\ Y_{21} \\ : \\ : \\ Y_{m t}\end{array}\right] ; U_{t}=\left[\begin{array}{c}U_{1 t} \\ U_{21} \\ : \\ : \\ U_{m t}\end{array}\right]$

Where: $Y_{t}$ include $\mathrm{m}$ the lag of random walk variables; $\mathrm{u}$ is the white noise; $s_{t}$ : vector elements are determined, maybe include constants, linear trend, or polynomials; $A$ is a square matrix of size $(\mathrm{m} \mathrm{x} \mathrm{m}), i=1,2 \ldots \mathrm{n} ; s_{t}=\left(s_{1 t}, s_{2 t} \ldots\right.$ $\left.s_{m t}\right)$

Advantages of the VAR model are as follows: this method fits with the research, there is no need to worry about determining which variables are endogenous or are exogenous; because all variables of the VAR model are endogenous; the sample size fit the model estimation; the method can be applied to equations.

The percentage of annual GDP growth at market prices is based on constant local currency. GDP is the sum of gross value added by all resident producers in the economy plus any product taxes and minus any subsidies not included in the value of the products.

The inflation is measured by the consumer price index and reflects the annual percentage change in the cost to the average consumer of acquiring a basket of goods and services. 
Table 2: VAR optimum lag selection criteria

\begin{tabular}{l}
\begin{tabular}{|l|c|c|c|c|c|c|}
\hline Lag & Log L & LR & FPE & AIC & SC & HQ \\
\hline 0 & -91.17327 & NA & 24.48437 & 8.873645 & 8.973123 & 8.895234 \\
\hline 1 & -84.05214 & $12.20765^{*}$ & $18.25749^{*}$ & $8.576394^{*}$ & $8.874829^{*}$ & $8.641162^{*}$ \\
\hline
\end{tabular} \\
*indicates lag order selected by the criterion \\
LR: sequential modified LR test statistic (each test at 5\% level) \\
\hline
\end{tabular}

The dataset is collected from the World Development Index (WDI) that is the main dataset on development indicators of the World Bank and compiled from official international sources. It presents available and accurate data on current global development.

The dataset is to analyse and forecast impulse response between the inflation rate and GDP growth rate, in case of inflation, what should the Government do? The results below show the control of the Government's monetary policy to grow the GDP. The results are described in the section below.

\section{Results}

As mentioned in the methodology and data set above, the results were tested by individual null hypotheses such as stationary time series test, optimal lag test and vector autoregression estimates. Besides, null hypotheses also were tested to select the good-fit and statistically significant model such as the Granger causality test, a cointegration test, VAR residual serial correlation, impulse response and the stability condition test and these null hypotheses.

The sample is tested to consider a stationary or nonstationary time series. If both the two variables are nonstationary time series, it has the mean value change over time or the value of variance change over time or both. The result of the unit root test shows as follows (see Table 1):

The results show that all tests have critical values greater than the test statistics and 0.0548 of Prob* is greater than $t_{\alpha=0.05}$, that is, the inflation variable is non-stationary time series. And the test statistics is greater than all test critical values and $t_{\alpha=0.05}$ is greater than the 0.0092 of Prob* i.e., the GDP variable is stationary time series. These variables are tested at lag (0) with $1 \%, 5 \%$ and $10 \%$ levels (see table 1 ). So, the variable is tested at the first difference.

The results in Table 1 show that the INF variable is the stationary series time at lag (1) with $1 \%, 5 \%$ and $10 \%$. These results are used to find out VAR optimum lag selection criteria. So, when building a VAR model, one needs to determine the optimum lag. The optimal latency was selected based on the Akaike information standards (AIC), the Schwarz information standard (SC) and the Hannan Quinn (HQ) information standard. Any delay that makes the above statistics receive the minimum value is considered the optimum lag of the model. This model is selected by (AIC) (see Table 2).
After the Likelihood-ratio (LR), Final Prediction Error (FPE), Akaike Information Criterion (AIC), Schwarz Information Criterion (SC) were tested, the optimum is selected for the VAR model. In the VAR model, the AIC standard suggests an optimum lag of 1 , considering macroeconomics, lag 1 is very suitable. So, the test shows that at lag 1, the VAR model has no statistical error. Thus, the statistical tests of the VAR model are reliable (see Table 3).

The Granger causality test is used in research to answer whether or not the change of INF variable occurs by GDP variable and vice versa. In the VAR model, each set of variables is regressed based on its past value and the value of other present variables. The relationship of the variables is tied together, introducing the lag of the variables in each equation as well as the correlation expansion among the "white noise" of the different equations. One of the common uses of the VAR model is causal testing between variables (see Table 4). A cointegration test is used to establish if there is a correlation between the time series in the long term. The cointegration tests identify scenarios where two or more non-stationary time series are integrated in a way that they cannot deviate from equilibrium in the long term. The tests are used to identify the degree of sensitivity of two variables (see Table 4).

Table 3: VAR model at the selected optimum lag (1) - Vector Autoregression Estimates

\begin{tabular}{|l|c|c|}
\hline Model & GDP & D(INF,1) \\
\hline GDP (-1) & 0.312554 & 4.063733 \\
\hline & $(0.19985)$ & $(1.33546)$ \\
\hline D (INF (-1),1) & {$[1.56395]$} & {$[3.04295]$} \\
\hline & -0.024716 & -0.474747 \\
\hline & $(0.02666)$ & $(0.17813)$ \\
\hline C & {$[-0.92721]$} & {$[-2.66522]$} \\
\hline & 4.337979 & -25.99263 \\
\hline & $(1.28749)$ & $(8.60344)$ \\
\hline
\end{tabular}

Note: Standard errors in () \& t-statistics in [] 
Table 4: VAR Granger Causality/Block Exogeneity Wald Tests and Johansen Cointegration Test

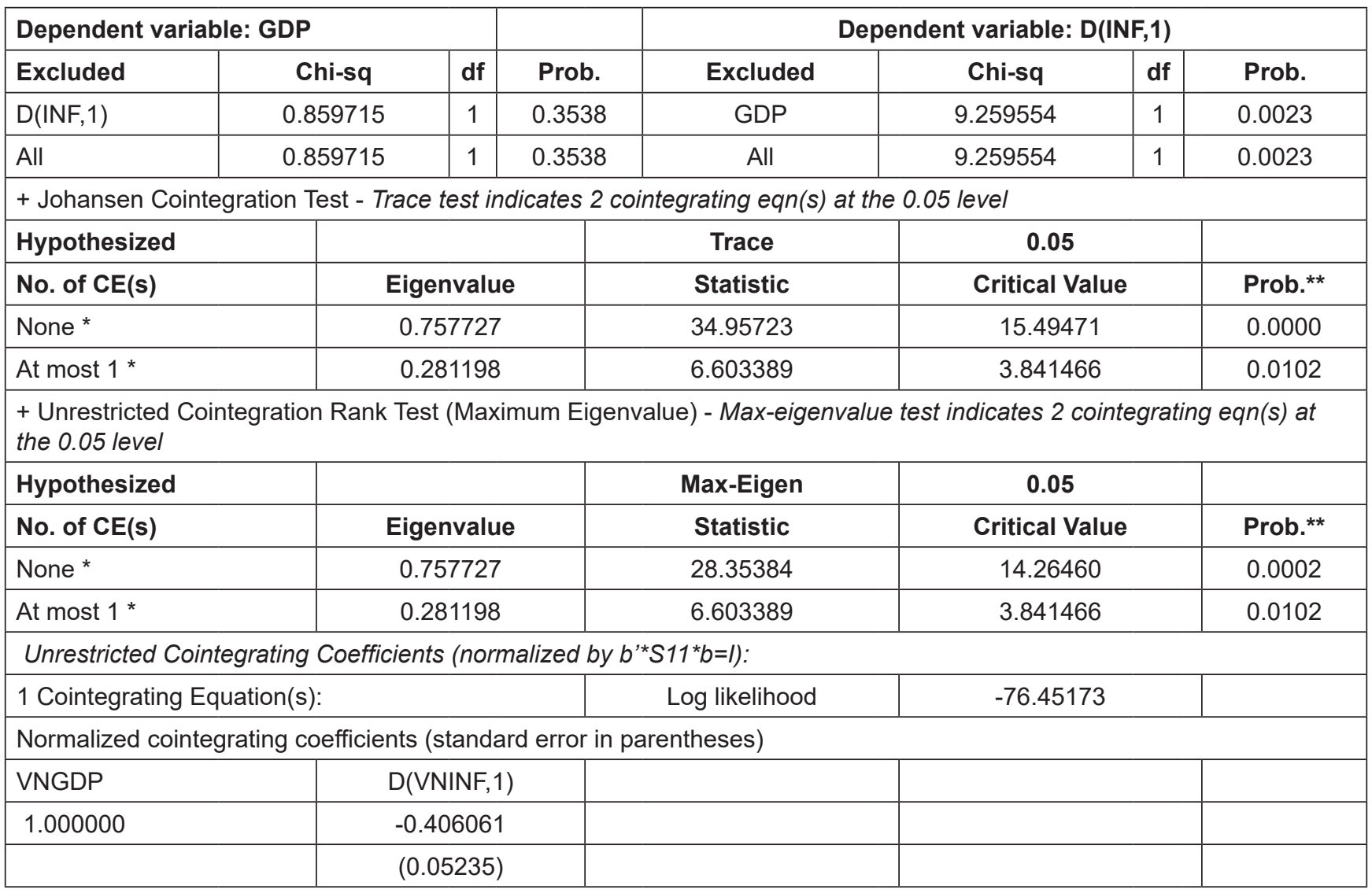

* denotes rejection of the hypothesis at the 0.05 level; ${ }^{* *}$ MacKinnon-Haug-Michelis (1999) p-values

Table 5: VAR Residual Serial Correlation LM Tests

\begin{tabular}{|c|c|c|c|c|c|c|}
\hline Lag & LRE* stat & df & Prob. & Rao F-stat & df & Prob. \\
\hline 1 & 9.492528 & 4 & 0.0499 & 2.687012 & $(4,30.0)$ & 0.0502 \\
\hline 2 & 5.467072 & 4 & 0.2426 & 1.446480 & $(4,30.0)$ & 0.2431 \\
\hline 3 & 3.966863 & 4 & 0.4105 & 1.023835 & $(4,30.0)$ & 0.4110 \\
\hline 4 & 1.288153 & 4 & 0.8634 & 0.318215 & $(4,30.0)$ & 0.8635 \\
\hline \multicolumn{7}{|c|}{ Null hypothesis: No serial correlation at lags 1 to $\mathrm{h}$} \\
\hline Lag & LRE* stat & df & Prob. & Rao F-stat & df & Prob. \\
\hline 1 & 9.492528 & 4 & 0.0499 & 2.687012 & $(4,30.0)$ & 0.0502 \\
\hline 2 & 14.23456 & 8 & 0.0759 & 2.059522 & $(8,26.0)$ & 0.0784 \\
\hline 3 & 15.26488 & 12 & 0.2273 & 1.393502 & $(12,22.0)$ & 0.2410 \\
\hline 4 & 16.20659 & 16 & 0.4386 & 1.026245 & $(16,18.0)$ & 0.4752 \\
\hline
\end{tabular}


It is known, if adjacent residuals are correlated, one residual can predict the next residual. In statistics, this is known as autocorrelation. This correlation represents explanatory information that the independent variables do not describe. Models that use time-series data are susceptible to this problem. So, residual analysis is a useful class of techniques for the evaluation of the goodness of fit model. Checking the underlying assumptions is important since most linear regression estimators require a correctlyspecified regression function and independent and identically distributed errors to be consistent (see Table 5).

Variance decomposition refers to the breakdown of the forecast error variance for a specific time horizon. The variance decomposition can indicate which variables have short-term and long-term impacts on the GDP and INF variables. Besides, the variance decomposition is to consider the percentage of the fluctuation in a time series attributable to the variables at select time horizons (see Table 6).

For the Impulse Response Analysis of VAR Models, impulse response analysis is an important step in econometric analysis, which uses vector autoregressive models. The main purpose is to describe the evolution of the model's both GDP and INF variables in reaction to a shock in these variables (see Figure 1).

The dynamically-stable model is considered after fitting the VAR that is tested by Roots of Characteristic Polynomial to check the dynamical stability condition. If all the eigenvalues lie inside the unit circle, the VAR satisfies stability condition. Because the modulus of each eigenvalue is strictly less than 1, the estimates satisfy the eigenvalue stability condition. Besides, specifying the graph option produced a graph of the eigenvalues with the real components on the $\mathrm{x}$-axis and the complex components on the y-axis. The graph below indicates visually that these eigenvalues are well inside the unit circle. The results are the basis for assessing the impact of inflation rate on real GDP growth in Vietnam over the period: from 1996 to 2018, and several indicators on Vietnam's economic growth that is shown in the discussion (see Figure 2).

Response of D(VNINF,1) to VNGDP Innovation using Cholesky (d.f. adjusted) Factors

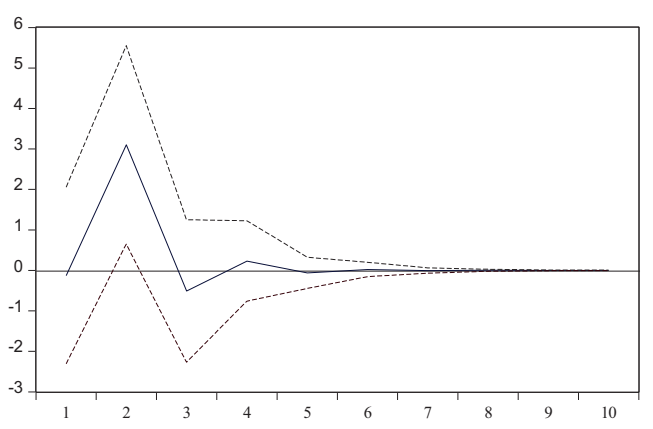

Figure 1: Impulse Response

Inverse Roots of AR Characteristic Polynomial

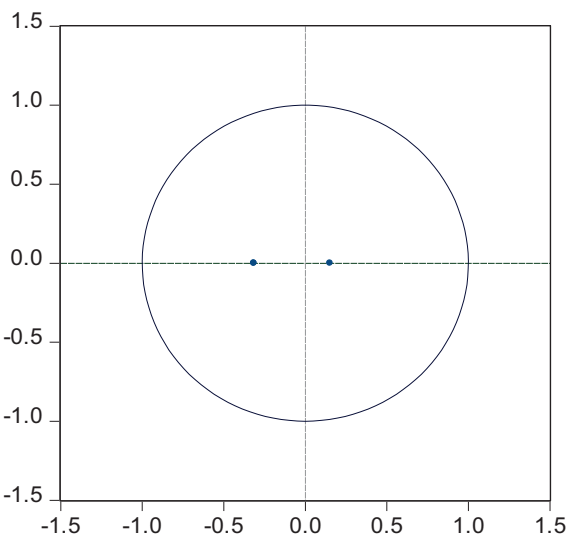

Figure 2: Dynamically stable test

Table 6: Variance Decomposition

\begin{tabular}{|l|c|c|c|c|c|c|c|}
\hline Variance Decomposition of GDP: & \multicolumn{4}{c|}{ Variance Decomposition of D(INF,1): } \\
\hline Period & S.E. & GDP & D(INF,1) & Period & S.E. & GDP & D(INF,1) \\
\hline 1 & 0.748118 & 100.0000 & 0.000000 & 1 & 4.999176 & 0.064355 & 99.93565 \\
\hline 2 & 0.794411 & 97.58241 & 2.417591 & 2 & 6.342958 & 23.93130 & 76.06870 \\
\hline 3 & 0.794667 & 97.52041 & 2.479587 & 3 & 6.393906 & 24.18501 & 75.81499 \\
\hline 4 & 0.794807 & 97.50797 & 2.492028 & 4 & 6.401697 & 24.25661 & 75.74339 \\
\hline 5 & 0.794814 & 97.50706 & 2.492936 & 5 & 6.402324 & 24.26120 & 75.73880 \\
\hline 6 & 0.794815 & 97.50696 & 2.493041 & 6 & 6.402393 & 24.26177 & 75.73823 \\
\hline 7 & 0.794815 & 97.50695 & 2.493051 & 7 & 6.402399 & 24.26182 & 75.73818 \\
\hline 8 & 0.794815 & 97.50695 & 2.493052 & 8 & 6.402400 & 24.26183 & 75.73817 \\
\hline 9 & 0.794815 & 97.50695 & 2.493052 & 9 & 6.402400 & 24.26183 & 75.73817 \\
\hline 10 & 0.794815 & 97.50695 & 2.493052 & 10 & 6.402400 & 24.26183 & 75.73817 \\
\hline Cholesky Ordering: GDPD(INF,1) & \multicolumn{5}{l}{} \\
\hline
\end{tabular}




\section{Discussion}

The objective of the study is to analyse the impact of inflation on the GDP growth of Vietnam via the collected sample. The VAR model also is applied to build the GDP growth forecast model. The results show that inflation has had an impact on GDP growth and these two variables passed the Granger causality test and the cointegration test.

The unit root test results show that the GDP variable is the stationary time series at lag (0) with $1 \%, 5 \%$ and $10 \%$, after comparing statistic and test critical values, which is the value of the test critical values is less than the value of the statistic test. $|-3.805090|$ of the statistic test is greater than test critical values that are $|-3.769597|$ at $1 \%,|-3.004861|$ at $5 \%$ and $|-2.642242|$ at $10 \%$. However, the INF variable is the non-stationary time series at lag $(0)$ with $1 \%, 5 \%$ and $10 \%$ because value of the statistic test is less than the critical values when $|-2.958428|<|-3.769597|$ at $1 \%,|-3.004861|$ at $5 \%$ and $>|-2.642242|$ at $10 \%$ with prob ${ }^{*} 0.0548>0.05$ $\left(t_{\alpha}\right)$. So, the INF variable is stationary time series lag $(0)$ with $10 \%$ that is uncertain. Thus, this variable is tested at the first difference and is the stationary time series at lag (1) with $1 \%, 5 \%$ and $10 \%$ when $|-5.821173|$ of critical values $>|-3.808546|,|-3.020686|$ and $|-2.650413|$ of the critical values at $1 \%, 5 \%$ and $10 \%$ with prob $0.0001<0.05\left(t_{\alpha}\right)$ (see table 1).

The result of unit root test of two series time of GDP and INF shows that, considering the original series, the GDP variable is stationary at lag (0) and the INF variable is not. After the variable D (INF) is tested the first-order difference that both these variables are stationary at lag (0) and lag (1) i.e., the variance and the covariance are constant at different lags, even though the time series is determined at any time. Therefore, both variables tend to return to the mean and the variations around the mean are the same. Thus, the data series is suitable for analysis in the next steps for the optimal model.

The above problem shows that Vietnam's inflation does not directly impact real GDP growth in the current year, but will impact on the GDP growth after a year, which means that in case the Government supplies money quantity in circulation, it cannot impact on the GDP growth in the current year, which only impacts on the GDP growth next year. These results fit completely with the collected sample.

The results show that one of VAR optimum lag selection criteria is selected at lag (1) because the AIC is 8.576394*. This is the basis to estimate the VAR model that is the goodness-fit model as follows:

The forecast VAR Model:

$$
\begin{aligned}
\text { Model (1): GDP }= & \mathrm{C}(1,1) \times \mathrm{GDP}(-1)+\mathrm{C}(1,2) \\
& \times \mathrm{D}(\operatorname{INF}(-1), 1)+\mathrm{C}(1,3)
\end{aligned}
$$

$$
\begin{aligned}
& \text { Model (2): D }(\mathrm{INF}, 1)=\mathrm{C}(2,1) \times \mathrm{GDP}(-1)+\mathrm{C}(2,2) \\
& \times \mathrm{D}(\operatorname{INF}(-1), 1)+\mathrm{C}(2,3) \\
& \mathrm{GDP}=0.312 \times \operatorname{GDP}(-1)-0.025 \mathrm{D}(\operatorname{INF}(-1), 1)+4.34 \\
& \mathrm{D}(\mathrm{INF}, 1)=4.064 \times \mathrm{GDP}(-1)-0.475 \times \mathrm{D}(\operatorname{INF}(-1), 1) \\
& -25.99
\end{aligned}
$$

Both VAR models have a correlation difference, the VAR model (1) shows that the GDP variable and the inflation variable are negatively correlated, that is high inflation, due to the continuous money supply growth, has caused decreased GDP in the long term. This is similar to Keynesian theory and the studies that show that the relationship between economic growth and inflation is nonlinear. Therefore, the VAR model (2) shows that these variables are positively correlated, because of the moderate inflation rate that relevantly grown money supply to the economic growth, encouraged GDP growth. Combining these two models, the relationship between these two variables is a line curve (see Table 3).

As it is known, the Granger causality test implies a correlation between present variable value and past values other variables, but not variables interdependence. This test shows the sign of one-way correlation. The economic growth rate displays a causal relationship with the inflation rate, but the inflation rate doesn't display a causal relationship with the economic growth rate. The results are the goodness-fit model because the inflation rate and growth rates are causal when the inflation rate has a one-year lag compared to economic growth. It means that when the money quantity supplies go into circulation, it doesn't impact on economic growth at the moment, but it will have this impact one year later (see Table 4).

Results on Table 4 shows that the cointegration of the independent variables is statistically significant at $5 \%$. So, in the long run, the inflation negatively impacts on economic growth, i.e., the inflation rate increases at $1 \%$ in the long run, the GDP drop to about $0.41 \%$ (assuming that other factors are constant). The cointegration between GDP and INF variables, when finding out the optimum lag through testing the lag of the both GDP and D(INF,1) variables, was tested by the Johansen Cointegration Test. The results show that the trace statistics of 34.95723 and 6.603389 are greater than the critical values of 15.49471 and 3.841466 at $5 \%$. So, the hypothesis $H_{0}$ is rejected, and $H_{1}$ is accepted, i.e., the GDP and INF variables existed in two cointegrating equations at the 0.05 level.

The correlation coefficient $r$ gives a measure of the relationship between economic growth and the inflation rate. It gives the percentage of the variation explained by the model. This residual serial correlation report showed that 
all Probs are greater than $t_{\alpha(0.05)}$ at lag from 1 to 4 . So, the correlation coefficient is not residual, and the sample fit to VAR model and statistical significance.

In the analyzed variables impact in the medium and longterm, the variance decomposition test is applied to forecast the inflation and economic growth impacts for the next 10 years. The period from the first year to the fifth year (called a medium term), the endogenous impact level of economic growth decreases gradually from $97.58 \%$ to $97.507 \%$. The period from the sixth year to the tenth year (called a long term), the impact level of economic growth is a constant $(97.506 \%)$. In the medium term, the endogenous impact level of inflation decreases gradually from $99,93565 \%$ to $75,73818 \%$ in the period from the first year to the seventh year. In the long term, it is constant $(75,73817 \%)$. It was found the endogenous impact of inflation is lag at 1 year compared to the endogenous effects of economic growth. The results show that, in the medium term, inflation rate impacts on the economic growth rate and this impact rate increased gradually. This impact begins from the second year to the seventh year, which is from $23.93130 \%$ to $24.26182 \%$. After, this impact is stabilized at $24.26183 \%$. However, the economic growth rate very slowly impacts on the inflation rate, such as the increased impact rate of $2.417591 \%, 2.479587 \%$ to $2.493051 \%$, from the second year to the seventh year. And then, this impact is stabilized at $2.493052 \%$.

In the first year, inflation responded to impulse very high economic growth. This shows that the shock of money supply into the economy has caused a reaction to growing the GDP. However, in the third year, inflation caused a negative reaction to the GDP, i.e., it caused GDP to go down after that economic growth gradually stabilized in the next years (see Figure 1).

As mentioned above, the VAR model is considered to be dynamically stable if there is a residual of stationary time series, and all coefficients of the characteristic polynomial are in the unit circle or the estimated Modulus is less than 1. Therefore, after estimating VAR, it is necessary to verify the stability of the modes. Determining the rest of the residual can be used as a unit root test. It indicates that the selected sample has stability, is goodness-fit with the model and statistically significant (see Figure 2).

\section{Conclusions}

Different countries' inflation and economic growth are a topic discussed by many authors. Some studies suggested a low inflation rate to stimulate economic growth, while a few studies suggested a high inflation rate to grow the economy fast. This issue is only fit for each country's economy and a specific research context. Besides, the selected methodology and model play an important role in result analysis and evaluation and is the basis for building a suitable model for research objectives. Thus, each author selected different models and methodologies to analyse and evaluate inflation and economic growth, depending on their research objectives. So, this paper selected the VAR methodology and model to analyze and evaluate inflation and economic growth. The goal is to consider endogenous variables, i.e., the dynamics of endogenous inflation and economic growth are considered by the VAR methodology and model to analyze inflation and economic growth. This paper's goal is to consider the dynamics of endogenous inflation and economic growth such as impulse response analysis, cointegrating test, Granger causality, the shock of the economy, etc.

The research results and the discussions above show the importance of inflation and economic growth. Any country is concerned about inflation index for economic growth and sustainability. Because, if the inflation rate exceeds the impulse response, it causes decreasing GDP growth. Therefore, scholars and macro managers should consider the following issues:

The inflation and economic growth exist with a oneway impact in the medium and long term from inflation rate to economic growth. So, the Government needs to have a comprehensive solution among macroeconomic policies, monetary policy, fiscal policy and other policies to control and maintain inflation and stimulate growth. In Vietnam's economy, the impulse response is forecast in the second year. It is dynamically stable in the third year.

In the long term, it is necessary to set up measures to promote economic growth and control inflation at an appropriate level. However, the research results show that the inflation rate positively impacts on economic growth in the first year and does not cause inflation. Further, the inflation rate responds by impulse to economic growth in the second year, as mentioned above. But, in the long term, the Government needs to have appropriate monetary policies to regulate inflation to stimulate economic growth at the beginning of the fourth year.

The Government should set a priority goal for sustainable economic growth. Besides, the Government needs to set specific goals to ensure that economic growth and inflation are controled in the long term. Because the inflation impacts on the economic growth with a lag of one year, the Government should not expect a high growth rate by loosening monetary policy, which will cause high inflation.

The result shows that economic growth and inflation are in cointegration and the inflation impacts on economic growth at lag a year. Therefore, the Government should not pursue economic growth by maintaining the inflation rate in the long term. Besides, the Government needs to take the appropriate goal to stabilize the inflation in the fourth year to promote sustainable economic growth and avoid money 
supply shocks. In the long term, if the inflation rate grows faster than the economic growth rate, the economy will be hit by high inflation that causes the economy to go down.

\section{References}

Al-Khulaifi, A. S. (2018). An Empirical Study on Inflation and Economic Growth in Qatar. International Journal of Economics and Financial Research, 4(9), 292-296.

Bhusal, T. P., \& Silpakar, S. (2012). Growth and inflation: Estimation of threshold point for Nepal. Economic Journal of Development Issues, 13(1), 131-138. doi:10.3126/ejdi.v13i0.7216

Carolina, T. (2015). Inflation and economic growth in an open developing country: the case of Brazil. Cambridge Journal of Economics, 3(9), 1263-1280.

Dinh, D. V. (2018). World crude oil prices impact on consumer price index. Advances and Applications in Statistics, 52(1), 33-54. doi:10.17654/AS052010033

Dinh, D. V. (2019a). Analysed money supply and inflation: evidence from vietnam economy. Advances and Applications in Statistics, 56(2), 125-142. doi:10.17654/AS056020125

Dinh, D. V. (2019b). Applied Individual Investment Risk Measurement Method to Forecast Expected Return Rate. International Journal of Applied Mathematics and Statistics, $58(3), 60-72$.

Dinh, D. V. (2019c). Money supply and inflation impact on economic growth. Journal of Financial Economic Policy, 12(1), 121-136. doi:10.1108/JFEP-10-2018-0152

Dinh, D. V. (2020a). Forecasting domestic credit growth based on ARIMA model: Evidence from Vietnam and China. Management Science Letters, 10(5), 1001-1010.

Dinh, D. V. (2020b). Optimal Inflation Threshold and Economic Growth: Ordinal Regression Model Analysis. Journal of Asian Finance, Economics and Business, 7(5), 91-102. doi:10.13106/ jafeb.2020.vol7.no5.091

Gulnaz, H., Sidra, N., \& Atta, M. (2017). Threshold Modeling for Inflation and GDP Growth. MPRA Paper ID 79649, 1-24. https://mpra.ub.uni-muenchen.de/id/eprint/79649

Kanchan, D., \& Chandan, K. M. (2011). Relationship between Inflation and Economic Growth in Malaysia An Econometric Review. International Conference on Economics and Finance Research, 4(1), 415-419. Available at: http://www.ipedr.com/ vol4/82-F10100.pdf

Emi, N., Jón, S., \& Miao, L. (2016). Are Chinese Growth and Inflation Too Smooth? Evidence from Engel Curves. American Economic Journal: Macroeconomics, 8(3), 113-144. doi:10.3386/w19893

Fakhri, H. (2011). Relationship between inflation and economic growth in Azerbaijani economy: is there any threshold effect?
MPRA Paper ID 33494, 1-9. Available at: https://mpra.ub.unimuenchen.de/33494/3/MPRA_paper_33494.pdf

Faraji, K., \& Kenani, M. (2012). Impact of inflation on economic growth: a case study of Tanzania. Asian Journal of Empirical Research, 3(4), 363-380. Available at: http://www.aessweb. com/pdf-files/1-3(4)2013-AJER-363-380.pdf

Khairul, K. S., \& Md. Sazib, M. (2017). Inflation and Economic Growth: An Empirical Evidence of Bangladesh (1986-2016). International Journal of Economics and Financial Issues, 7(5), 454-464. Available at: https://www.econjournals.com/index. php/ijefi/article/view/5385

Kumar, K., \& Paramanik, R. N. (2020). Nexus between Indian Economic Growth and Financial Development: A Non-Linear ARDL Approach. Journal of Asian Finance, Economics and Business, 7(6), 109-116. doi:10.13106/jafeb.2020.vol7.no6.109

Mishkin, F. (2016). The Economics of Money, Banking and Financial Markets. Boston, MA: Pearson Addison-Wesley.

Muhammad, A., Imran, S. C., \& Fatima, F. (2011). Does Inflation Affect Economic Growth? The case of Pakistan. Pakistan Journal of Social Sciences, 31(1), 51-64.

Mustafa, A. M., \& Sivarajasingham, S. (2019). Dynamic Linkages between Food Inflation and Its Volatility: Evidence from Sri Lankan Economy. Journal of Asian Finance, Economics and Business, 6(4), 139-145. doi:10.13106/jafeb.2019.vol6.no4.139

Nurlanova, N. K., Omarov, A. K., \& Satpayeva, Z. T. (2020). Methodological Approaches to Estimation of Economic Growth and Sustainable Development: Kazakhstan's Experience. Journal of Asian Finance, Economics and Business, 7(4), 317-324. doi:10.13106/jafeb.2020.vol7.no4.317

Patrick, E., Prudence, A. O., \& Edmond, H. (2013). The Relationship Between Gdp Growth Rate And Inflationary Rate In Ghana: An Elementary Statistical Approach. Academic Research International, 4(5), 310-318. Available at: http:/www.savap. org.pk/journals/ARInt./Vol.4(5)/2013(4.5-31).pdf

Rao, B. B. (2007). Cointegration for the Applied Economist. London, UK: Palgrave Macmillan.

Robert J, B. (2013). Inflation and Economic Growth. Annals of Economics and Finance, 14(1), 121-144.

Shahzad, H., \& Shahnawaz, M. (2011). Inflation and Economic Growth: Evidence from Pakistan. International Journal of Economics and Finance, 5(3), 262-276. doi:10.5539/ijef. v3n5p262

Shapan, C. M. (2016). Inflation and Its Impacts on Economic Growth of Bangladesh. American Journal of Marketing Research, 2(1), 17-26.

Thanabalasingam, V. (2013). Inflation and Economic Growth: A Dynamic Panel Threshold Analysis for Asian Economies. GRIPS Discussion Paper, 23(4), 12-17. doi:10.1016/j. asieco.2013.04.001 